\title{
Persepsi Peserta Terhadap Aplikasi Mobile JKN Berbasis Technology Acceptance Model Di Klinik Pratama Surya Medika Semarang
}

\author{
JKN Mobile \\ Application with \\ Technology Acceptance \\ Model
}

\author{
Harsono, Sigit Sugiharto, Rinayati \\ Prodi Perekam dan Informasi Kesehatan Universitas Widya Husada Semarang, Indonesia \\ Email :mr.harsono77@gmail.com
}

\section{ABSTRACT}

The JKN Mobile Application is an application designed by BPJS Health to balance the current increasing use of mobile technology and to provide easy acces and convenience for JKN participants online. This study aims to determine the extent to which JKN participants perceptions of the JKN Mobile Application are measured using the TAM (Technology Acceptance Model) analysis model based on the usefulness (perceived usefulness) and ease of use (perceived ease of use)

This research is a quantitative descriptive study using a cross-sectional research design with a research sample of 38 JKN participants registered at the Pratama Surya Medika Clinic Semarang through random sampling with the research instrument used is a questionnaire. The results showed that the overall JKN mobile application was rated $82,5 \%$ as very useful and $84 \%$ very easy to operate so it was very helpful and supportive for JKN participants in getting health services at the Pratama Surya Medika Clinic Semarang

Keywords: JKN Participant Perception, JKN Mobile Application, TAM (Technology Acceptance Model)

\begin{abstract}
ABSTRAK
Aplikasi Mobile JKN merupakan aplikasi yang didesain oleh BPJS Kesehatan untuk mengimbangi meningkatnya penggunaan teknologi mobile saat ini serta dalam rangka memberikan kemudahan akses dan kenyamanan bagi peserta JKN secara online. Penelitian ini bertujuan untuk mengetahui sejauh mana persepsi peserta JKN terhadap Aplikasi Mobile jkn yang diukur menggunakan model analisis TAM (Technology Acceptance Model) berdasarkan kebermanfaatan (Perceived Usefulness) dan kemudahan (Perceived Ease of Use)

Penelitian ini merupakan penelitian deskriptif kuantitatif menggunakan desain penelitian crossectional dengan sampel penelitian 38 orang peserta JKN yang terdaftar di Klinik Pratama Surya Medika Semarang melalui teknik pengambilan sampel secara random sampling dengan instrument penelitian yang digunakan adalah kuesioner. Hasil penelitian menunjukkan hasil bahwa secara keseluruhan aplikasi mobile jkn dinilai $82,5 \%$ sangat bermanfaat dan $84 \%$ sangat mudah dalam pengoperasianya sehingga sangat membantu dan menunjang peseserta jkn dalam mendapatkan layanan kesehatan di Klinik Pratama Surya Medika Semarang
\end{abstract}

Kata Kunci : Persepsi Peserta JKN, Aplikasi Mobile JKN, TAM (Technology Acceptance Model)

\section{PENDAHULUAN}

Diera revolusi industri 4.0 ini kita dituntut untuk mampu berdampingan dan mengikuti perkembangan dan kemajuan IPTEK yang serba digital dan otomatisasi, hal ini pula berdampak pada dunia kesehatan. Peran teknologi dalam dunia kesehatan termasuk hal yang sangat penting terutama dalam meningkatkan kualitas serta mutu pelayanan kesehatan (Mustika, 2015). Tak bisa dipungkiri bahwa teknologi yang saat

\section{JIMKES}

$$
\begin{array}{r}
\text { Jurnal Ilmiah Manajemen } \\
\text { Kesatuan } \\
\text { Vol. } 9 \text { No. } 2,2021 \\
\text { pp. } 447-454 \\
\text { IBI Kesatuan } \\
\text { ISSN } 2337-7860 \\
\text { E-ISSN } 2721-169 X \\
\text { DOI: } 10.37641 / \text { jimkes.v9i2.793 }
\end{array}
$$

Submitted:

Accepted:

JUNI 2021 
JKN Mobile

Application with

Technology Acceptance

Model

448

ini sedang melejit salah satunya adalah smartphone, berdasarkan data Kemeninfo jumlah pengguna smartphone di Indonesia mencapai 167 juta orang atau $89 \%$ dari total penduduk Indonesia dengan rata-rata usia pengguna 25-34 tahun (Hanum, 2021). Dengan jumlah pengguna aktif smartphone yang telah mencapai lebih dari 100 juta orang, Indonesia diperkirakan akan tercatat menjadi negara terbesar keempat di dunia setelah Cina, India dan Amerika (Rahmayani, 2015). Smartphone sudah menjadi gaya hidup masyarakat khususnya kalangan usia muda di era globalisasi. Hal ini juga terbukti berdasarkan survey yang mengatakan bahwa kalangan remaja masih menjadi basis kuat smartphone (Resti, 2015). Sebuah penelitian di Jepang menyebutkan bahwa sebuah aplikasi kesehatan yang diberi nama iHeart dan digunakan secara mobile serta berbasis lokasi ini mampu mengirim tekanan darah dan denyut jantung ke rumah sakit serta unit perawatan darurat. Hasil penelitian tersebut menyimpulkan bahwa iHeart dapat mengurangi kemungkinan kritis seorang pasien dalam keadaan darurat, hal ini membuktikan bahwa pemanfaatan aplikasi kesehatan secara online dapat menyelamatkan lebih banyak nyawa (Keikhosrokiani. P, N. Mustaffa, N. Zakaria, 2013). Aplikasi mobile adalah aplikasi yang dirancang khusus untuk platform mobile seperti iOS, android, atau windows mobile yang bisa digunakan kapanpun dan dimanapun. Kemajuan teknologi ini dapat membantu pengolahan data atau informasi secara cepat, efisien, dan akurat. Kemajuan dari aplikasi mobile dapat dilihat dari banyaknya aplikasi yang tersedia yang dapat memudahkan penggunanya dalam membantu pekerjaannya(Pressman, Roger S. and Maxim, 2014)

Mencermati kondisi tersebut serta dalam rangka untuk meningkatkan pelayanan kepada peserta JKN, BPJS Kesehatan telah mendesain dan melaunching aplikasi mobile JKN. Aplikasi Mobile JKN menyediakan informasi yang lengkap seputar Program JKN yang memuat fasilitas layanan mulai dari merubah data peserta, pengecekan iuran serta konsultasi kedokter secara online, peserta dapat memanfaatkan aplikasi untuk pengurusan kepesertaan tanpa harus datang langsung ke kantor BPJS (News Jamkes.com, 2019). Berdasarkan data BPJS Kesehatan pada tahun 2017 tercatat pengguna Aplikasi Mobile JKN versi Android sebanyak > 1.000 .000 user dan Aplikasi Mobile JKN versi iOS sebanyak > 2.000 (BPJS, 2020).

Klinik Pratama Surya Medika Semarang merupakan Fasilitas Kesehatan Tingkat Pertama dengan jumlah peserta JKN mencapai 9.000 peserta yang tersebar diwilayah Semarang Barat dimana jumlah kunjungan peserta JKN yang melakukan kunjungan pemeriksaan di Klinik Pratama Surya Medika Semarang setiap bulanya pada masa pandemi covid ini mencapai kurang lebih 1.000 peserta. Berdasarkan informasi yang diperoleh dari petugas pelayanan kesehatan pada klinik Pratama Surya Medika Semarang didapatkan data bahwa jumlah peserta JKN yang memanfaatkan Aplikasi Mobile-JKN hanya berkisar $5-10 \%$ dengan fitur layanan yang digunakan yaitu no antrian periksa dan konsultasi dokter online. Berdasarkan data peserta JKN di Klinik Surya Medika Semarang yang telah memanfaatkan aplikasi mobile JKN, peneliti tertarik untuk melakukan evaluasi pemanfaatan aplikasi mobile jkn tersebut berdasarkan persepsi pengguna dari sisi kemudahan (Perceived Ease of Use) dan kemanfaatan (Perceived Usefulness)

\section{METODOLOGI PENELITIAN}

Penelitian ini merupakan penelitian deskriptif kuantitatif dengan menggunakan desain penelitian crossectional yang dilakukan pada bulan Februari 2021 dengan lokasi pengambilan sampel penelitian yaitu di Klinik Pratama Surya Medika Semarang dimana besaran jumlah sampel penelitian sejumlah 38 orang peserta JKN yang terdaftar di Klinik Pratama Surya Medika Teknik pengambilan sampel menggunakan random sampling, instrumen penelitian yang digunakan adalah kuesioner. Data dalam penelitian ini meliputi data primer dan data sekunder, data primer dalam penelitian ini yaitu kuesioner kemudahan dan kebermanfaatan sistem informasi Mobile JKN yang diisi oleh responden, sedangkan data sekunder dalam penelitian ini adalah studi 
kepustakaan berupa buku dan jurnal. Analisis data yang digunakan dalam penelitian ini yaitu dengan menggunakan model Technology Acceptance Model (TAM) yang meliputi aspek persepsi pengguna terhadap kebermanfaatan dan kemudahan sistem informasi aplikasi mobile JKN dan menggunakan skala likert. Technology Acceptance Model (TAM) atau Model Penerimaan Teknologi merupakan salah satu teori tentang penggunaan sistem teknologi informasi yang dianggap sangat berpengaruh dan umumnya digunakan untuk menjelaskan penerimaan individual terhadap penggunaan sistem teknologi informasi (Jogianto, 2008)

\section{Aspek Persepsi Pengguna Terhadap Kebermanfaatan}

Kuesioner persepsi pengguna berdasar aspek kebermanfaatan terdiri dari 6 pernyataan yang meliputi :

Tabel 1

Kuesioner Persepsi Pengguna berdasar aspek kemanfaatan (perceived of usefulness)

\begin{tabular}{|c|c|c|c|c|c|}
\hline \multirow{2}{*}{ No } & \multicolumn{5}{|l|}{ Pernyataan } \\
\hline & KEMANFAATAN (Perceived Of Usefulness) & STS & TS & $\mathbf{S}$ & SS \\
\hline 1 & $\begin{array}{l}\text { Dengan Aplikasi Mobile JKN dapat membantu saya } \\
\text { dalam memperoleh informasi tentang data peserta dan } \\
\text { keluarga secara cepat }\end{array}$ & & & & \\
\hline 2 & $\begin{array}{l}\text { Menggunakan Aplikasi Mobile JKN membantu saya } \\
\text { dalam memperoleh informasi tentang tagihan dan } \\
\text { pembayaran iuran dengan mudah }\end{array}$ & & & & \\
\hline 3 & $\begin{array}{l}\text { Melalui Aplikasi Mobile JKN membantu saya dalam } \\
\text { memperoleh data layanan kesehatan di fasilitas kesehatan } \\
\text { dengan cepat dan mudah }\end{array}$ & & & & \\
\hline 4 & $\begin{array}{l}\text { Dengan Aplikasi Mobile JKN saya dapat menyampaikan } \\
\text { pengaduan dan permintaan informasi seputar JKN tanpa } \\
\text { harus datang ke kantor BPJS }\end{array}$ & & & & \\
\hline 5 & $\begin{array}{l}\text { Dengan Aplikasi Mobile JKN saya dapat mendaftar dan } \\
\text { mengubah data kepesertaan dengan mudah tanpa harus ke } \\
\text { Kantor BPJS }\end{array}$ & & & & \\
\hline 6 & $\begin{array}{l}\text { Dengan Aplikasi Mobile JKN membantu saya dalam } \\
\text { melakukan pendaftaran pelayanan di fasilitas kesehatan } \\
\text { tingkat pertama tanpa harus datang ke Faskes Klinik } \\
\text { Pratama Surya Medika Semarang }\end{array}$ & & & & \\
\hline
\end{tabular}

\section{Aspek Persepsi Pengguna Terhadap Kemudahan}

Kuesioner persepsi pengguna berdasar aspek kemudahan terdiri dari 5 pernyataan yang meliputi :

Tabel 2

Kuesioner Persepsi Pengguna berdasar aspek kemudahan (perceived Easy of Use)

\begin{tabular}{clcc}
\hline \multirow{2}{*}{ No } & \multicolumn{1}{c}{ Pernyataan } & STS TS S SS \\
\hline \multirow{2}{*}{1} & $\begin{array}{l}\text { KEMUDAHAN (Perceived Easy Of Use) } \\
\text { Untuk belajar mengoperasikan Aplikasi Mobile JKN bagi } \\
\text { saya tidak sulit }\end{array}$ & \\
\hline 2 & $\begin{array}{l}\text { Saya dapat dengan mudah mengoperasikan aplikasi Mobile } \\
\text { JKN dalam melakukan pendaftaran dan perubahan data } \\
\text { peserta }\end{array}$ & \\
\hline Dalam pencarian informasi kepesertaan dan anggota & \\
keluarga saya dapat dengan mudah mengoperasikan dalam \\
Aplikasi Mobile JKN
\end{tabular}

Application with

Technology Acceptance Model 
JKN Mobile

Application with

Technology Acceptance

Model

Skala Likert digunakan untuk mengukur persepsi pengguna terhadap kebermanfaatan dan kemudahan sistem informasi aplikasi mobile JKN

Tabel 3

Skala Likert

\begin{tabular}{|c|c|c|}
\hline No & $\begin{array}{c}\text { Tingkat } \\
\text { Penerimaan/Jawaban }\end{array}$ & Skor \\
\hline 1 & Sangat Setuju (SS) & 4 \\
\hline 2 & Setuju (S) & 3 \\
\hline 3 & Tidak Setuju (TS) & 2 \\
\hline 4 & Sangat Tidak Setuju (STS) & 1 \\
\hline
\end{tabular}

Penilaian interpretasi responden terhadap kebermanfaatan dan kemudahan sistem informasi aplikasi mobile JKN dilakukan dengan menggunakan rumus indek $\%$ :

Total Skor/jml skor likert x 100 Maka : 100/4 : 25

Sehingga hasil (I) yaitu 25 , berikut kriteria interpretasi skor berdasarkan interval :

Tabel 4

Kriteria Interpretasi Responden

\begin{tabular}{lll}
\hline No & \multicolumn{1}{c}{ Interpretasi $\%$} & \multicolumn{1}{c}{ Ket } \\
\hline 1 & $0 \%-24,99 \%$ & Sangat Tidak Bermanfaat/Mudah \\
\hline 2 & $25 \%-49,99 \%$ & Tidak Bermanfaat/Mudah \\
\hline 3 & $50 \%-74,99 \%$ & Bermanfaat/Mudah \\
\hline 4 & $75 \%-100 \%$ & Sangat Bermanfaat/Mudah \\
\hline
\end{tabular}

\section{HASIL DAN PEMBAHASAN}

Hasil penelitian dan pengolahan data yang telah dilakukan pada klinik pratama surya medika semarang didapatkan hasil sebagai berikut :

1. Persepsi Peserta Jkn-Kis Terhadap Sistem Informasi Mobile Jkn Berbasis TAM (Technology Acceptance Model) di Klinik Pratama Surya Medika Semarang berdasarkan aspek kemanfaatan (perceived of usefulness)

Aspek kemanfaatan (perceived of usefulness) merupakan kemanfaaatan dari sistem informasi aplikasi Mobile JKN bagi peserta JKN di Klinik Pratama Surya Medika dalam mendapatkan layanan kesehatan. Tabel 5 merupakan rekapitulasi jawaban responden dari sisi aspek kemanfaatan (perceived of usefulness)

Tabel 5

Rekapitulasi Jawaban Repsonden

berdasarkan aspek kemanfaatan (perceived of usefulness) 


\begin{tabular}{|c|c|c|c|c|c|}
\hline \multirow[t]{2}{*}{ No } & \multirow{2}{*}{$\begin{array}{c}\text { Pernyataan } \\
\text { KEMANFAATAN (Perceived Of Usefulness) }\end{array}$} & \multicolumn{4}{|c|}{$\begin{array}{c}\text { Hasil Penilaian } \\
\text { Responden }\end{array}$} \\
\hline & & STS & TS & $\mathbf{S}$ & SS \\
\hline 1 & $\begin{array}{l}\text { Dengan Aplikasi Mobile JKN dapat membantu saya } \\
\text { dalam memperoleh informasi tentang data peserta } \\
\text { dan keluarga secara cepat }\end{array}$ & 1 & & 20 & 17 \\
\hline 2 & $\begin{array}{l}\text { Menggunakan Aplikasi Mobile JKN membantu saya } \\
\text { dalam memperoleh informasi tentang tagihan dan } \\
\text { pembayaran iuran dengan mudah }\end{array}$ & 1 & & 22 & 15 \\
\hline 3 & $\begin{array}{l}\text { Melalui Aplikasi Mobile JKN membantu saya dalam } \\
\text { memperoleh data layanan kesehatan di fasilitas } \\
\text { kesehatan dengan cepat dan mudah }\end{array}$ & 1 & & 25 & 12 \\
\hline 4 & $\begin{array}{l}\text { Dengan Aplikasi Mobile JKN saya dapat } \\
\text { menyampaikan pengaduan dan permintaan } \\
\text { informasi seputar JKN tanpa harus datang ke kantor } \\
\text { BPJS }\end{array}$ & 1 & & 25 & 12 \\
\hline 5 & $\begin{array}{l}\text { Dengan Aplikasi Mobile JKN saya dapat mendaftar } \\
\text { dan mengubah data kepesertaan dengan mudah } \\
\text { tanpa harus ke Kantor BPJS }\end{array}$ & 1 & 1 & 20 & 16 \\
\hline 6 & $\begin{array}{l}\text { Dengan Aplikasi Mobile JKN membantu saya } \\
\text { dalam melakukan pendaftaran pelayanan di fasilitas } \\
\text { kesehatan tingkat pertama tanpa harus datang ke } \\
\text { Faskes Klinik Pratama Surya Medika Semarang }\end{array}$ & 1 & 3 & 22 & 12 \\
\hline
\end{tabular}

JKN Mobile

Application with

Technology Acceptance

Model

451

Dari data pada tabel 5 kemudian dilakukan interpretasi perhitungan skor berdasarkan skala likert, hasil interpretasi perhitungan skor berdasarkan aspek kemanfaatan (perceived of usefulness) disajikan dalam table 6 sebagai berikut :

Tabel 6

Interpretasi perhitungan skor

\begin{tabular}{|c|c|c|c|c|c|c|}
\hline \multirow[b]{2}{*}{$\begin{array}{c}\text { No } \\
\text { Pernyataan }\end{array}$} & STS & TS & $\mathbf{S}$ & SS & \multirow{2}{*}{$\begin{array}{c}\text { Total Skor } \\
\text { Per } \\
\text { Pernyataan } \\
\sum \text { f.n }\end{array}$} & \multirow{2}{*}{$\begin{array}{c}\text { Skor } \\
\text { tertinggi per } \\
\text { pernyataan } \\
\text { Y (4.38) }\end{array}$} \\
\hline & f.n & f.n & f.n & f.n & & \\
\hline 1 & 1 & 0 & 60 & 68 & 129 & 152 \\
\hline 2 & 1 & 0 & 66 & 60 & 127 & 152 \\
\hline 3 & 1 & 0 & 75 & 48 & 124 & 152 \\
\hline 4 & 1 & 0 & 75 & 48 & 124 & 152 \\
\hline 5 & 1 & 2 & 60 & 64 & 127 & 152 \\
\hline 6 & 1 & 6 & 66 & 48 & 121 & 152 \\
\hline Total Skor & 6 & 8 & 402 & 336 & 752 & 912 \\
\hline \multicolumn{5}{|c|}{$\begin{array}{l}\text { Hasil Penilaian Intepretasi (Total Skor Per } \\
\text { Pernyataan /Total Skor Tertinggi) x } 100\end{array}$} & \multicolumn{2}{|c|}{$(752 / 912) \times 100=82,5 \%$} \\
\hline
\end{tabular}

Berdasarkan tabel 6 menunjukan bahwa nilai rata-rata persepsi peserta jkn-kis terhadap sistem informasi mobile jkn berbasis TAM (Technology Acceptance Model) di Klinik Pratama Surya Medika Semarang dari aspek kebermanfaatan (perceived of usefulness) sebesar 82,5\% dengan kriteria interpretasi responden sangat bermanfaat dengan adanya aplikasi mobile JKN bagi peserta JKN KIS sehingga sangat membantu dalam mendapatkan layanan kesehatan di Klinik Pratama Surya Medika Semarang Kebermanfaatan Sistem Informasi antara lain mempercepat pekerjaan, meningkatkan kinerja dan produktifitas, efektifitas, mempermudah pekerjaan dan membantu pelayanan(Nurhayati, 2019). Perceived usefulness dapat diukur dengan indikator 
JKN Mobile

Application with

Technology Acceptance

Model

meningkatkan produktivitas, membuat kerja lebih efektif, dan mempercepat suatu pekerjaan(Yahyapour, 2008).

2. Persepsi Peserta Jkn-Kis Terhadap Sistem Informasi Mobile Jkn Berbasis TAM (Technology Acceptance Model) di Klinik Pratama Surya Medika Semarang berdasarkan aspek kemudahan (perceived easy of use)

Aspek kemudahan (perceived easy of use) merupakan kemudahan peserta JKN dalam pengoperasian sistem informasi mobile JKN terhadap layanan kesehatan yang diberikan oleh BPJS

Tabel 7

Rekapitulasi Jawaban Repsonden berdasarkan aspek kemudahan (perceived Easy of Use)

\begin{tabular}{clccc}
\hline \multirow{2}{*}{ No } & \multicolumn{1}{c}{ Pernyataan } & STS & S & SS \\
\cline { 2 - 4 } & KEMUDAHAN (Perceived Easy Of Use) & 20 & 17 \\
\hline 1 & $\begin{array}{l}\text { Untuk belajar mengoperasikan Aplikasi Mobile JKN } \\
\text { bagi saya tidak sulit }\end{array}$ & 1 & 17 & 15 \\
\hline 2 & $\begin{array}{l}\text { Saya dapat dengan mudah mengoperasikan aplikasi } \\
\text { Mobile JKN dalam melakukan pendaftaran dan } \\
\text { perubahan data peserta }\end{array}$ & 1 & 25 & 13 \\
\hline 3 & $\begin{array}{l}\text { Dalam pencarian informasi kepesertaan dan anggota } \\
\text { keluarga saya dapat dengan mudah mengoperasikan } \\
\text { dalam Aplikasi Mobile JKN }\end{array}$ & $\begin{array}{l}\text { Saya dapat melakukan pendaftaran pelayanan } \\
\text { kesehatan di Fasilitas Kesehatan di Klinik Pratama } \\
\text { Surya Medika melalui pengoperasian Aplikasi } \\
\text { Mobile JKN dengan mudah }\end{array}$ & 21 & 15 \\
\hline 5 & $\begin{array}{l}\text { Aplikasi Mobile JKN secara keseluruhan mudah } \\
\text { dioperasikan }\end{array}$ & 1 & 22 & 15 \\
\hline
\end{tabular}

Dari data pada tabel 7 kemudian dilakukan interpretasi perhitungan skor berdasarkan skala likert, hasil interpretasi perhitungan skor berdasarkan aspek kemudahan (perceived Easy of Use) disajikan dalam table 8 sebagai berikut :

Tabel 8

Interpretasi perhitungan skor

\begin{tabular}{|c|c|c|c|c|c|c|}
\hline \multirow[b]{2}{*}{$\begin{array}{c}\text { No } \\
\text { Pernyataan }\end{array}$} & STS & TS & $\mathbf{S}$ & SS & \multirow{2}{*}{$\begin{array}{l}\text { Total Skor } \\
\text { Per } \\
\text { Pernyataan } \\
\sum \text { f. n } \\
\end{array}$} & \multirow{2}{*}{$\begin{array}{c}\text { Skor } \\
\text { tertinggi per } \\
\text { pernyataan } \\
\text { Y (4.38) }\end{array}$} \\
\hline & f. $n$ & f. $n$ & f. $n$ & f. $\mathbf{n}$ & & \\
\hline 1 & 1 & & 60 & 68 & 129 & 152 \\
\hline 2 & 1 & 2 & 63 & 60 & 126 & 152 \\
\hline 3 & & & 75 & 52 & 127 & 152 \\
\hline 4 & & 4 & 63 & 60 & 127 & 152 \\
\hline 5 & & 2 & 66 & 60 & 128 & 152 \\
\hline 6 & 1 & & 60 & 68 & 129 & 152 \\
\hline Total Skor & 3 & 8 & 387 & 368 & 766 & 912 \\
\hline \multicolumn{5}{|c|}{$\begin{array}{c}\text { Hasil Penilaian Intepretasi (Total Skor /Skor } \\
\text { Tertinggi) x } 100\end{array}$} & \multicolumn{2}{|c|}{$(766 / 912) \times 100=84 \%$} \\
\hline
\end{tabular}

Berdasarkan tabel 8 menunjukan bahwa nilai rata-rata persepsi peserta jkn-kis terhadap sistem informasi mobile jkn berbasis TAM (Technology Acceptance Model) di Klinik Pratama Surya Medika Semarang dari aspek kemudahan (perceived Easy of 
Use) sebesar $\mathbf{8 4} \%$ dengan kriteria interpretasi responden sangat mudah didalam pengoperasian aplikasi mobile JKN bagi peserta JKN KIS sehingga sangat membantu dalam mendapatkan layanan kesehatan di Klinik Pratama Surya Medika Semarang, semakin mudah sistem dioperasikan maka akan semakin baik pula tingkat penerimaan dari sistem tersebut (Andriani, 2020). Ada beberapa indikator dalam kemudahan menggunakan teknologi informasi, meliputi: komputer sangat mudah dipelajari, komputer mengerjakan dengan mudah apa yang diinginkan oleh pengguna, komputer sangat mudah untuk meningkatkan keterampilan pengguna, komputer sangat mudah untuk dioperasikan (Wibowo, 2006).

\section{PENUTUP}

Berdasarkan hasil penelitian dan pembahasan penelitian diatas dapat disimpulkan bahwa persepsi peserta jkn terhadap Aplikasi Mobile JKN di Klinik Pratama Surya Medika Semarang berbasis TAM (Technology Acceptance Model) menunjukan hasil bahwa secara keseluruhan Aplikasi tersebut dinilai sangat bermanfaat dan sangat mudah dalam pengoperasianya sehingga sangat membantu dan menunjang peserta jkn dalam mendapatkan layanan kesehatan di Klinik Pratama Surya Medika Semarang

\section{DAFTAR PUSTAKA}

[1] Andriani, R. (2020). Evaluasi Sistem Informasi Menggunakan Technology Acceptance Model dengan penambahan variable eksternal. Teknologi Informasi Dan Ilmu Komputer, 7(3).

[2] Arikunto, S. (2006). Prosedur Penelitian Suatu Pendekatan Praktik Edisi Revisi VI. Rinerka Cipta.

[3] BPJS, H. (2020). BPJS Kesehatan Sediakan Informasi Menarik Lewat Mobile JKN. BPJS.

[4] Hanum, Z. (2021). 89\% Penduduk Indonesia gunakan smartphone. Https://Mediaindonesia.Com/Humaniora/389057/Kemenkominfo-89-

Penduduk-Indonesia-Gunakan-Smartphone, Sumber: https://mediaindonesia.com/humaniora/389057/kemenkominfo-89penduduk-indonesia-gunakan-smartphone

[5] Jogianto, H. (2008). Analisis dan Desain Sistem Informasi. ANDI OFFSET.

[6] Keikhosrokiani. P, N. Mustaffa, N. Zakaria, M. S. (2013). Wireless positioning techniques and location-based services: a literature review. Multimedia and Ubiquitous Engineering. Lecture Notes in Electrical Engineering, 240.

[7] Mustika. (2015). Perkembangan Teknologi Informasi dalam Aspek Kesehatan. Press, UGM.

[8] News Jamkes.com. (2019). Apa itu aplikasi mobile JKN. News Jamkes.

[9] Notoatmodjo, S. (2010). Metodologi Penelitian Kesehatan. Rineka Cipta.

[10] Nurhayati. (2019). Analisis Tingkat Penerimaan Pengguna Terhadap Teknologi Sistem Informasi Rekam Medis di PKU Muhamadiya Karanganyar. SMIKNAS.

[11] Pressman, Roger S. and Maxim, B. R. (2014). Software Engineering: A Practitioner's Approach.

[12] Rahmayani, I. (2015). Indonesia Raksasa Teknologi Digital. Kemenkoinfo. https://kominfo.go.id/content/detail/6095/indonesia-raksasateknologidigital-asia/0/sorotan_media

[13] Resti. (2015). Penggunaan Smartphone di kalangan Mahasiswa Fakultas Ilmu Sosial dan Ilmu Politik Universitas Riau. Jom Fisip.

[14] Susanto, A. (2004). Sistem Informasi Manajemen konsep dan pengembangannya. Lingga Jaya.
JKN Mobile

Application with

Technology Acceptance

Model 
JKN Mobile

Application with

Technology Acceptance

Model

454
[15] Wibowo, A. (2006). Kajian Tentang Perilaku Pengguna Sistem Informasi Dengan Pendekatan Technology Acceptance Model (TAM. Universitas Budi Luhur.

[16] Yahyapour, N. (2008). Determining Factors Affecting Intention to Adopt Banking Recommender System, Case of Iran. Lulea University of Technology Division of Industrial Marketing and E-commerce. 